\section{Shining mirrors at Apache Point}

Washington

UsING a new mirror technology and a new design, a consortium of five universities is planning to build a 3.5-metre telescope in New Mexico's Sacramento Mountains. With a recently awarded grant of $\$ 3.74$ million from the National Science Foundation (NSF), the Apache Point Observatory is scheduled to begin operation in 1988 .

Apache Point's mirror is a smaller version of the type of mirror likely to be used for the National New Technology Telescope (NNTT). It is cast using borosilicate glass and spun as it is cast, allowing a closer first approximation of the desired parabolic shape. The new techniques result in lighter and less expensive mirrors, bringing the cost of observatories the size of Apache Point to a level manage-

\section{More ocean dives}

Tokyo

THE US submersible Alvin is scheduled to make its first visit to Japanese waters in 1987. Scientists from the United States and Japan have agreed plans for at least 85 dives to investigate the back- and fore-arc regions of the western Pacific.

Dives will be made in three areas; the Mariana Trough, a back-arc spreading centre, the Mariana fore-arc region which overlies the subducting Pacific Plate and the Sumisu back-arc rift northwest of the Ogasawara Islands.

Among the features to be investigated are a methane plume billowing up to $700 \mathrm{~m}$ above the floor of the Mariana Trough; diapiric seamounts bulging out of the seafloor of the Mariana fore-arc region; a chain of volcanoes that trends across the back-arc basin from the Northern Mariana Arc; and the Sumisu Rift which is thought to be a modern analogue of the setting for the Kuroko massive sulphide ore deposits on the Japanese mainland.

Funding for the project, which will run up a bill of a few million dollars, will be covered almost entirely by the US side.

Follow-up investigations of the survey area by the Japanese submersibles Shinkai 2000 , and, when completed, Shinkai 6500 , are expected to be made in the near future according to Hiroshi Hotta, director of the Deep-Sea Research Department of the Japan Marine Science and Technology Center (JAMSTEC), who will participate in the Alvin survey. In a recent review of policy, JAMSTEC decided to devote attention to the spreading ridges and rift basins in close proximity to Japan, such as the Okinawa Trough and Sumisu Rift. Also, in future, foreign scientists will be allowed to board Shinkai 2000.

David Swinbanks able by a small research consortium.

The five universities are not all equal partners in the project. The University of Chicago and the University of Washington will both contribute 31 per cent of the project costs, Princeton University and New Mexico State University 16 per cent and Washington State University the remaining 6 per cent. Bruce Margon of the University of Washington, chairman of the Astrophysical Research Consortium formed by the universities to build Apache Point, says viewing time will be allocated in accordance with contributions. Margon estimates the total cost of the project will be $\$ 10$ million.

Using private funds to build large observatories is a new trend. Several university groups have announced plans to build 7.5-metre telescopes, and the Keck Telescope, a 10-metre segmented mirror telescope that will be operated by California Institute of Technology and the University of California, is already under construction in Hawaii.
A $\mathrm{T}$ long last the world has an international forum that could help avert the total destruction of tropical forests. All the major tropical timber producing and consuming nations agreed in Geneva last week to put into operation the International Tropical Timber Agreement. Among its clauses are those aimed at "sustainable utilization and conservation of tropical forests and their genetic resources, and at maintaining the ecological balance

The agreement has been twenty years in the making and has been held up for more than a year by a squabble over the location of its headquarters. Only after a fresh meeting broke up in disarray was agreement finally reached: the headquarters are to be established in Yokohama and its executive director is to be $\mathrm{Mr}$ Haji Freezailah, deputy director-general of forestry for Malaysia. This arrangement neatly ties together the world's biggest tropical timber producer. Malaysia, and the biggest consumer, Japan. But argument is continuing over the budget for the new organization and nobody yet knows how effective a body it will be.

The UN-sponsored agreement does not establish a cartel and has no powers to fix prices or to regulate exports. But it does provide a talking shop for 41 nations that between them account for 95 per cent of the world's trade in tropical timber and. uniquely for a trade agreement, it has among its principal goals the preservation of tropical forests so that they may be
Several factors make Apache Point attractive. The observatory is the first designed for complete remote operation. Margon points out that this allows users to wait for appropriate conditions without having to make a pilgrimage to New Mexico. It will also be possible to divide a night's observation among astronomers at different institutions.

The performance of Apache Point may well exceed that of larger telescopes for certain problems. Keeping the structure housing the telescope to an absolute minimum will reduce atmospheric distortion caused by the heat from the observatory's own instruments. Sacramento Peak is also one of the darkest points in the United States, making it an attractive spot for observing extremely low light objects.

Perhaps most alluring to consortium members is that once built, Apache Point will be theirs to use as they please. Observing time is oversubscribed at the Kitt Peak National Observatory in Arizona and Cerro Tololo Inter-American Observatory in Chile. At Apache Point. says Margon, users will be able to tackle longer term and speculative projects.

Joseph Palca

\title{
A little hope for tropical forests
}

managed as a renewable resource. Other aims, also intended to benefit timber producers in the developing world, are to promote research and development in tropical forest management and utilization and to encourage the processing of timber in producing countries to promote their industrialization and export earnings.

The Scandinavian countries have taken the lead in introducing into the agreement clauses aimed at protecting tropical forests. Voting rights have been equally distributed among producer and consumer countries and if a majority can be found there is every chance that these clauses can be translated into action. The chief obstacle is likely to be lack of money. Several thousand million dollars need to be spent to halt tropical deforestation and the producer countries naturally feel that the bulk of the burden should be borne by the wealthy consumers. As a practical first step, the World Wildlife Fund is urging the appointment of an experienced forest ecologist to help run the agreement and prevent forest disasters: it also wants at least $\$ 5$ million to be set aside for conservation projects in the short term and says that prices for tropical timber should include the cost of reforestation, conservation and research on sustainable management. It is likely to be next spring, at the earliest, before the organization announces its initial budget and there is any indication of how successful it might be.

Alun Anderson 